\title{
POLÍTICAS PARA A IMPLEMENTAÇÃO DA LEI 10639/03 EM UM MUNICÍPIO BRASILEIRO: O DISCURSO OFICIAL E O DISCURSO PEDAGÓGICO
}

\author{
POLICIES FOR THE IMPLEMENTATION OF LAW 10639/03 IN A BRASILIAN CITY: THE OFFICIAL \\ DISCOURSE AND THE PEDAGOGICAL DISCOURSE
}
POLITICAS PARA LA APLICACIÓN DE LA LEY 10639/03 EN UNA CIUDAD BRASILEÑA: EL DISCURSO OFICIAL Y EL DISCURSO PEDAGÓGICOTÍTULO EM ESPANHOL

\author{
Benedito Gonçalves Eugênio ${ }^{1}$ \\ José Jackson Reis dos Santos ${ }^{2}$ \\ Janyne Barbosa Souza ${ }^{3}$
}

\section{RESUMO}

Neste artigo, abordamos o discurso pedagógico acerca dos desafios e avanços no processo de discussão e implementação da Lei 10639/03 em uma Rede de Ensino de município do interior da Bahia. Os dados foram construídos a partir de análise de documentos (nacionais e locais) e entrevistas realizadas com três funcionárias da Secretaria Municipal de Educação e Cultura que acompanharam, em diferentes momentos, a implantação da política de educar para as relações etnicorraciais. Para a análise, tomamos alguns dos pressupostos presentes na teoria sociológica de Basil Bernstein. As conclusões assinalam que a implementação da Lei, por si só, não garantirá mudanças significativas nas relações históricas que excluem o negro na sociedade. As mudanças se constituem a partir de ações que podem ser coletivas e individuais.

PALAVRAS-CHAVE: Discurso pedagógico. Lei 10639/03. Relações raciais.

\section{ABSTRACT}

In this paper, approach the pedagogical discourse about the challenges and advances in the process of discussion and implementation of Law 10639/03 in a Network of Education in Bahia. Data were constructed from analysis of documents (national and local) and interviews with three employees of the Municipal Department of Education and Culture that followed, at different times, the implementation of the policy of education for etnicorraciais relations. For the analysis, we take some of the assumptions present in the sociological theory of Basil Bernstein. The findings indicate that the implementation of the Law, by itself, will not guarantee significant changes in historical relations that exclude the black in society. The changes are based on the actions that can be collective and individual.

KEYWORDS: Pedagogic discourse. Law 10639/03. Racial relations.

\footnotetext{
${ }^{1}$ Professor Adjunto da Universidade Estadual do Sudoeste da Bahia. Graduação e Programa de Pós-Graduação em Relações Étnicas e Contemporaneidade. Email: beneditoeugenio@bol.com.br>

${ }^{2}$ Doutorado em Educação -Universidade Federal do Rio Grande do Norte (UFRN). Professor Adjunto da Universidade Estadual do Sudoeste da Bahia (UESB) - Itapetinga - BA - Brasil. Email: jackson uesb@yahoo.com.br

${ }^{3}$ Mestre em Educação - Universidade Estadual do Sudoeste da Bahia (UESB). Professora na Rede Municipal de Ipiaú-Ba. Email: jany462@yahoo.com.br
}

(C) ETD- Educação Temática Digital Campinas, SP $\quad$ v.19 $\quad$ n.1 $\quad$ p. 283-304 jan./mar. 2017 
RESUMEN

Discutimos el discurso pedagógico sobre los retos y avances en el proceso de discusión y aplicación de la Ley 10639/03 en una Red de educación en la Bahía. Los datos se construyen a partir de análisis de documentos (nacionales y locales) y entrevistas con tres empleados de la Dirección Municipal de Educación y Cultura que siguieron, en diferentes momentos, la aplicación de la política de la educación para etnicorraciais relaciones. Para el análisis, tomamos algunos de los supuestos presentes en la teoría sociológica de Basil Bernstein. Los resultados indican que la aplicación de la Ley, por sí misma, no garantizará cambios significativos en las relaciones históricas que excluyen del negro en la sociedad. Los cambios se basan en las acciones que pueden ser colectiva e individual.

PALABRAS CLAVE: Discurso pedagógico. Ley 10639/03. Relaciones raciales.

\section{INTRODUÇÃO}

A Lei 10639/03, ao instituir a obrigatoriedade da educação para as relações etnicorraciais, alterou o artigo 26 da Lei de Diretrizes e Bases 9394/96, assim como impôs aos sistemas de ensino a necessidade de efetuar alterações no currículo, na formação continuada dos docentes, nas práticas de ensino e na gestão escolar, exigindo que escolas, secretarias de educação e instituições de ensino superior com cursos de licenciatura, a partir de diferentes possibilidades (cursos de formação continuada, realização de oficinas/seminários, criação de disciplinas), incorporassem a discussão sobre as relações etnicorraciais em seu cotidiano. Ao se propor a inclusão das relações etnicorraciais no currículo escolar, o objetivo não é impor uma prática idealizada (GOODSON, 1995), mas, ao contrário, é esperada uma mudança de visões e práticas que levem à adoção de um currículo não opressor, em que os conhecimentos dos africanos e afro-brasileiros se façam presentes, de forma que os estudantes de diferentes origens étnicas possam acessar um currículo não monocromático, isto é, para além da visão colonialista ocidental.

Evidentemente que ainda enfrentamos uma série de dificuldades para efetivar o trabalho com a educação das relações etnicorraciais nos sistemas de ensino e nas escolas, em particular, principalmente, a nosso ver, devido a duas questões: o mito da democracia racial e a crença na inexistência do racismo por parte de muitos docentes. Tal como pontou Hasenbalg (2005, p.241), “o mito da democracia racial brasileiro é indubitavelmente o símbolo integrador mais poderoso criado para desmobilizar os negros e legitimar as desigualdades raciais vigentes desde o fim do escravismo". Levando em consideração o que aponta Chauí (2000, p.12), o mito da democracia racial funciona, entre nós, como um semióforo, ou seja, "um signo trazido à frente ou empunhado para indicar algo que significa alguma outra coisa e cujo valor não é medido por sua materialidade e sim por sua força simbólica", o que pode nos ajudar a compreender as dificuldades persistentes para o trabalho com as relações etnicorraciais no currículo das escolas e também nos cursos de

(C) ETD-Educação Temática Digital Campinas, SP $\quad$ v.19 $\quad$ n.1 $\quad$ p. 283-304 jan./mar. 2017 
formação docente, por mais que se ampliem estudos acerca dessa temática, conforme podemos observar, por exemplo, no GT 21 da ANPED e no banco de dissertações e teses da Capes.

Estudos sobre a implementação da referida Lei, assim como as práticas pedagógicas direcionadas para a educação das relações etnicorraciais, têm se ampliado consideravelmente, conforme apontam Paula e Guimarães (2014), Filice (2010), Coelho e Silva (2013), Santos (2015). Efetuando um balanço de teses/dissertações e artigos científicos sobre formação de professores e relações raciais em duas bases de dados, quais sejam, Capes e Scielo, esses autores constatam que a partir do ano de 2003 houve ampliação das pesquisas que aliam a discussão da diversidade racial na formação docente. Assim:

A lei federal 10.639/2003 tornou-se um marco periodizador político, legal e histórico. A formação continuada, que até então era considerada uma panacéia para resolver os problemas do ensino e da aprendizagem na educação escolar básica de um modo geral, torna-se basilar para a implementação da obrigatoriedade do estudo da história e da Cultura Africana e Afro-brasileira, tendo em vista a formação inicial considerada lacunar ou mesmo insatisfatória neste campo (PAULA e GUIMARÃES, 2014, p.445).

Filice (2010, p.14), ao realizar estudo sobre o processo de implementação da referida Lei em municípios brasileiros, pontua para a importância de se inserir nas políticas direcionadas a uma educação antirracista as dimensões cultural, social e politica, principalmente como forma de desvelar "as formas de manifestação ideológica, simbólica e prática da cultura do racismo, materializado no preconceito e na discriminação racial". Essa autora evidencia como raça, classe e gestão estão presentes nas visões de mundo, ações e convicções de gestores da educação (UNDIME, SEB/MEC, SECD/MEC), representantes do movimento social negro (NEN-Núcleo de Estudos Negros), coordenadores de NEAB e gestores proativos (diretores de escolas que, de certa forma, contribuem para a implementação da Lei 10639/03).

Outro estudo importante e que objetivou mapear a produção brasileira desenvolvida nos programas de pós-graduação em Educação foi efetuado por Coelho e Silva (2013). As autoras selecionaram, para isso, PPGs cujas notas estavam acima de 4 na avaliação da Capes e dissertações/teses disponíveis no banco de dados da Capes cujo objeto investigado fosse referente à temática relações raciais e educação. Além disso, consultaram também os grupos de pesquisas cadastrados no diretório do CNPq e que apresentam aderência, seja no título ou nas linhas, à temática das relações raciais.

(C) ETD-Educação Temática Digital Campinas, SP v.19 $\quad$ n.1 $\quad$ p. 283-304 jan./mar. 2017 
Feito esse mapeamento, as autoras pontuam que:

\begin{abstract}
É interessante observar que há variações no tratamento dado às Relações Raciais, mas grande parte dos trabalhos a analisa enquanto política de ação afirmativa, como instrumento da educação antirracista (enquanto processo de socialização e, portanto, de interação com a cultura - ou intervenção nela - e pressuposto para a participação cidadã ou política), ou seja, a educação brasileira contemporânea seria um instrumento de subversão do preconceito e do racismo silenciado, existente na escola, em suas mais variadas formas (COELHO; SILVA, 2013, p. 122).
\end{abstract}

Um elemento a ser observado nos estudos que se propõem a analisar a implementação da educação das relações etnicorraciais é a ausência da discussão sobre o conceito e as teorias de implementação de políticas trazidas pelas ciências sociais. A implementação é aqui compreendida como momento importante na análise de políticas, pois é nele que "se concretiza o processo de conversão de intenções políticas em ações que terão consequências sobre um determinado aspecto da realidade social" (BARBOSA, 2014, p. 39).

Assim, estudos de análise acerca da implementação da Lei 10639/03, por nós considerada uma política pública de ação afirmativa, são imprescindíveis, principalmente ao constatarmos que após 12 anos de aprovação da referida Lei, realizar um trabalho que leve à adoção de práticas pedagógicas culturalmente orientadas (LADISON-BILLINGS, 2008) tem se mostrado um dos grandes desafios a serem enfrentados pela escola.

Para Gomes (2012), um dos desafios postos à escola na contemporaneidade, principalmente com a ampliação do direito à educação, é articular os diferentes tipos de conhecimentos dos diversos sujeitos sociais antes invisibilizados ou desconsiderados como sujeitos de conhecimentos. Os conhecimentos dos coletivos empobrecidos (ARROYO, 2013) repolitizam os currículos e demandam da escola, portanto, a necessidade de incorporar saberes e práticas em prol de uma educação emancipatória. Essa exigência pode ser evidenciada com a obrigatoriedade do ensino de história e cultura africana e afro-brasileira trazida pela Lei 10639/03.

Passados mais de 13 anos desde que a obrigatoriedade do ensino de História e cultura africana e afro-brasileira foi instituída, o que constatamos é que muitas redes de ensino ainda não implementaram o trabalho com a temática. Em diversos municípios, inclusive, sequer a discussão integra os planos municipais de educação, a formação continuada dos docentes e o trabalho cotidiano por meio do currículo praticado nas escolas. Isso significa dizer que, apesar da conquista expressa nos marcos legais, a escola que a população negra conhece ainda é uma escola que tem negado a sua existência, orientada

(C) ETD- Educação Temática Digital Campinas, SP $\quad$ v.19 $\quad$ n.1 $\quad$ p. 283-304 jan./mar. 2017 
pelo esquecimento e pela invisibilidade dessa população. Assim, a escola ainda se constitui como "[...] um não lugar para os negros" (ROMÃO, 2001, p. 17).

Neste artigo, apresentamos os resultados de uma pesquisa realizada no período 2013-2014. Abordamos o discurso pedagógico das gestoras acerca dos desafios e avanços no processo de discussão e implementação da Lei 10639/03 na Rede Municipal de Ensino de um município localizado na região sudoeste do Estado da Bahia. A escolha do município deve-se ao fato de ter sido o primeiro da região do sudoeste baiano a implementar uma política educacional de educar para as relações etnicorraciais por meio da criação de um Núcleo de Estudos sobre a História e Cultura Afro-Brasileira e Africana no âmbito da Secretaria Municipal de Educação e Cultura, responsável pelo oferecimento de cursos de formação continuada acerca da temática aos docentes, além de publicação de um decreto instituindo a educação das relações etnicorraciais como política municipal.

O município investigado está na zona limítrofe entre a caatinga e a zona da mata, possui uma população de 151.820 habitantes, segundo o último censo do IBGE e foi o primeiro a implantar a educação das relações etnicorraciais no currículo da educação básica na região do sudoeste baiano. Cercada de montanhas, a cidade sofre com o calor durante todo o ano. Em dias de verão, a temperatura pode chegar a $46 \circ \mathrm{C}$. No que se refere à educação, o município investigado possuía, em 2014, um total de 33.987 alunos matriculados na rede pública de ensino, assim organizada: Ensino Fundamental, abrange 23.708 alunos; o Ensino Médio, com 6.110 e o Ensino Pré-escolar, com 4.169.

Os dados foram construídos por meio de uma pesquisa qualitativa do tipo estudo de caso. A unidade de análise -ou caso - foi a materialização do discurso pedagógico para implementação da Lei 10.639/03 na rede municipal de ensino. O instrumento empregado para a recolha dos dados foi a entrevista. Realizamos entrevistas com servidoras da Secretaria Municipal de Educação e Cultura (SMEC), a quem foram atribuídos nomes fictícios e que participaram, em três gestões municipais, da política educacional do município. A seleção dos sujeitos investigados levou em consideração o fato de que elas acompanharam, em diferentes momentos, a implementação da política de educar para as relações etnicorraciais no município investigado.

Para a análise, tomamos alguns dos pressupostos presentes na teoria sociológica de Basil Bernstein (1996). Este autor ocupa um lugar de destaque no que se refere à teoria e à pesquisa no domínio do controle simbólico, produção, reprodução e mudança cultural. Foi influenciado pelo interacionismo simbólico, por Karl Marx e Emile Durkheim, entre outros. Seu pensamento oferece várias possibilidades de análise do campo da educação, uma vez

(C) ETD-Educação Temática Digital Campinas, SP v.19 $\quad$ n.1 $\quad$ p. 283-304 jan./mar. 2017 
que permite descrever agências específicas de reprodução cultural. De acordo com Santos (2003, p.25), Bernstein "elabora seus estudos dando centralidade às questões relacionadas ao processo de comunicação pedagógica que se constitui no mais importante meio de controle simbólico".

Neste artigo, enfatizamos a teoria do Discurso Pedagógico no que se refere ao contexto educacional formal, aos sistemas de ensino institucionalizados, sendo enfocadas questões referentes à comunicação pedagógica. De acordo com a teoria de Bernstein (1996), o discurso não diz respeito apenas à linguagem, mas aos tipos de ideologias e valores que estão por trás dos discursos. O discurso pedagógico busca compreender a produção, a distribuição e a reprodução do conhecimento oficial e como este conhecimento articula-se com as relações estruturalmente determinadas. Ao enfatizar a importância do estudo do discurso pedagógico, Bernstein tem como objetivo "descrever as práticas organizacionais, discursivas e de transmissão presentes nas agências pedagógicas e o processo por meio do qual a aprendizagem se faz de forma seletiva" (SANTOS, 2003, p.25).

Bernstein (1996, p. 234) ressalta que “[...] a comunicação pedagógica é o condutor de relações de classe; o condutor de relações de gênero; o condutor de relações religiosas, de relações regionais" e, também, acrescentamos, o condutor das relações etnicorraciais, posto que está diretamente ligada à relação de classe social. Logo, podemos considerar que a comunicação pedagógica é o condutor para padrões de dominação externas a ela própria.

Nessa perspectiva, Bernstein (1996, p.250) propõe um dispositivo pedagógico que tem regras internas que regulam a comunicação pedagógica e a torna possível, sendo tal dispositivo similar ao linguístico, que, para o teórico, se constitui em "[...] um sistema de regras formais, as quais regem as distintas combinações que fazemos ao falar e escrever".

Contudo, tais dispositivos variam de acordo com o contexto e não são independentes de ideologias, por isso são não estáveis, coadunando-se com a concepção de que não se pode tratar a linguagem, a cultura e o conhecimento, as relações sociais e, no caso desse trabalho, as relações etnicorraciais como totalidades estanques e isoladas, e sim como conjunto abertos e dinâmicos.

\section{A LEI 10639/03 NA REDE MUNICIPAL DE ENSINO INVESTIGADA}

A aprovação da Lei 10.639/03 impôs aos sistemas de ensino estaduais e municipais a necessidade de trabalhar com os discentes da educação básica a história e cultura africana e afro-brasileira, fruto da demanda histórica dos movimentos negros. Como nos alertam

(C) ETD-Educação Temática Digital Campinas, SP v.19 $\quad$ n.1 $\quad$ p. 283-304 jan./mar. 2017 
Pontes e Macedo (2011), a produção da política curricular de educar para as relações etnicorraciais

[...] envolveu um conjunto de articulações políticas no sentido de hegemonizar posições na esfera pública. Esse movimento em busca de hegemonia foi levado a cabo por diferentes atores sociais que se constituíram no processo mesmo de criar estratégias para que suas demandas fossem atendidas. Atores que, embora denominados genericamente de movimentos negros ou simplesmente negros, possuem identidades híbridas que, de forma alguma, podem ser reduzidas ao estereótipo, mesmo que as finalidades dessa redução sejam a de criar vínculos com vistas a reivindicações de direitos. Isso a que chamamos de movimentos negros ou de negros envolve antigas disputas por hegemonia em diferentes contextos $[\ldots]$

Quanto aos municípios, esses se organizaram das mais diversas formas: desde criação de disciplinas, organização de projetos, seminários até a perspectiva da folclorização da temática, principalmente por meio do que Santomé (1999) denomina de currículo turístico. No caso do município lócus e contexto da pesquisa realizada para a escrita deste artigo, foi decidido que haveria duas disciplinas a serem trabalhadas: "História e Cultura da África" e "História da Cultura Afro-Brasileira", conforme percebemos nos discursos de Carolina Maria.

No primeiro momento, nossa preocupação era tentar implantar a lei. Então, o primeiro trabalho realizado foi uma discussão com o Conselho e com algumas pessoas da comunidade e, principalmente, com o Sindicato dos Professores. Decidimos que fosse criada uma disciplina e seria trabalhada da $5^{\circ}$ a $8^{\circ}$ série com o professor de História. Então, implantamos no currículo a questão da Cultura Afro e também a questão de gênero. Implantamos a disciplina História e Cultura Afro Brasileira e Educação para a Sexualidade; eram os dois temas que a gente achava importantes começar a discussão (Carolina Maria).

Segundo a entrevistada Carolina Maria, essas disciplinas foram mantidas na parte diversificadas do currículo e também trabalhadas de maneira interdisciplinar. Naquele momento, chegou-se à conclusão de que o ideal seria trabalhar essas disciplinas e também inserir a temática desde a Educação Infantil. Além da implementação da Lei e da criação da disciplina História e Cultura Afro-Brasileira, foi implantado um Fórum Permanente sobre Educação e Diversidade Cultural e Etnicorracial, com o objetivo de promover a sensibilização sobre as questões raciais, constituindo-se em um espaço democrático de discussão sobre os problemas locais de exclusão social propondo políticas municipais afirmativas para os afrobrasileiros.

(C) ETD-Educação Temática Digital Campinas, SP v.19 $\quad$ n.1 $\quad$ p. 283-304 jan./mar. 2017 
O processo de mover um discurso de uma posição para outra é definido por Bernstein (1996) como recontextualização pedagógica. O autor afirma que "[...] quando um discurso é movido, por recontextualização, do seu contexto original para o contexto pedagógico, o discurso original é abstraído da sua base social, posição e relações de poder" (BERNSTEIN, 1996, p. 38). Assim, podemos citar as disciplinas escolares como exemplo de discursos recontextualizados, pois elas foram levadas do campo acadêmico e reposicionadas para servir a determinados propósitos no contexto escolar.

Nessa perspectiva, observamos que o discurso proveniente dos campos recontextualizadores, seja oficial ou pedagógico, muitas vezes funciona como um discurso regulativo do discurso pedagógico, na medida em que define o que deve ser dito e como deve ser dito. Essa relação de poder e controle dos campos recontextualizadores, mais especificamente do pedagógico, fica mais evidenciada quando analisamos os discursos das entrevistadas e elas definem o que deve ou não ser transmitido (conteúdos), assim como quais atividades devem ser realizadas de acordo com o conhecimento que se tem sobre as relações etnicorraciais.

Com a Lei 10639/03 promulgada, qual o caminho a ser trilhado? Como os municípios deveriam se orientar? De que forma implementá-la? Como trabalhar nessa perspectiva para que a lei tenha êxito e as diretrizes sejam aplicadas em sua integridade. Foi com esses questionamentos e inquietações que o Município investigado teve a preocupação inicial de implementação da Lei 10639/03.

Para atender às exigências propostas pela Lei 10.639/03 e para legalizar as ações realizadas, o município, por meio da Secretaria Municipal de Educação e Cultura (SMEC), assumiu em 2006, o compromisso de implementar políticas públicas de promoção da igualdade racial na rede municipal de ensino. A Lei Orgânica do Município, promulgada em 1990, em seu artigo 133, instituiu o Programa Municipal de Educação para Diversidade Cultural e Etnicorracial.

Os discursos das entrevistadas evidenciam como se configurou a inserção da temática etnicorracial no município. O marco inicial foi a implementação da Lei 10.639/03, objetivando atender, inicialmente, o que estava previsto pela referida Lei Federal.

A secretaria implantou essa lei em virtude da exigência do MEC e determinou que todas as escolas deveriam trabalhar com a temática história e cultura afrobrasileira. (Dandara).

(C) ETD- Educação Temática Digital Campinas, SP $\quad$ v.19 $\quad$ n.1 $\quad$ p. 283-304 jan./mar. 2017 
A temática da história e cultura afro-brasileira foi inserida na proposta curricular do município, por força da lei mesmo. Depois veio a pressão dos grupos, dos segmentos, isso ajudou a consolidar a mudança. (Lélia González).

A primeira preocupação nossa era tentar implantar a lei 10. 639/03. A gente precisava de um decreto para normatizar e dá legalidade à discussão da temática etnicorracial. (Carolina Maria).

Ao afirmarem que o processo de implementação da temática das relações etnicorraciais no município investigado se deu pela força e exigência da Lei Federal, podemos perceber a existência dos campos oficial e pedagógico. Esses dois campos têm se produzido nos embates e negociações permanentes entre o Estado e as instituições educacionais da sociedade civil organizada. Nesse sentido, o discurso pedagógico, do ponto de vista ideológico, não é neutro, tendo em vista que o fato do discurso se mover de um lugar para outro cria espaço para a atuação da ideologia.

As discussões no campo das questões etnicorraciais, no município investigado, no âmbito das políticas públicas, ganharam destaque com a criação de um grupo de trabalho, no ano de 2006, formado por representantes da Secretaria de Educação do Município para discussão e elaboração de uma política que considerasse a especificidade local, na perspectiva de ampliar o que preconizava a Lei 10.639/2003. Dentre as contribuições advindas desse grupo de trabalho, a elaboração do Decreto $n$ ㅇ 8.559/06, de 21 de dezembro de 2006, tornou-se um marco ao implementar a educação sobre as relações etnicorraciais e o ensino da temática de história e cultura afro-brasileira e africana, no Sistema Municipal de Ensino.

Há na teoria bernsteiniana dois modelos que sintetizam os principais conceitos de sua teoria: o modelo de reprodução e transformação cultural e o modelo do discurso pedagógico. Nesse último modelo, importa o que é transmitido como conhecimento educacional (MORAIS; NEVES, 2007). É importante pontuar que a produção e reprodução do discurso pedagógico envolvem um processo dinâmico. De acordo com Morais e Neves (2007, p.122):

Por um lado, os princípios dominantes que são transmitidos pelo discurso regulador geral reflectem posições de conflito e não relações estáveis. Por outro lado, há sempre fontes potenciais ou reais de conflito, resistência e inércia entre os agentes políticos e administrativos do campo de recontextualização oficial, entre os diversos agentes do campo de recontextualização pedagógica e entre o contexto primário do aquisidor e os princípios e práticas da escola. Além disso, os professores e os autores de manuais escolares podem sentir-se incapazes ou relutantes em reproduzir o código de transmissão educacional subjacente ao discurso pedagógico oficial. É este dinamismo que permite que a mudança tenha lugar.

(C) ETD-Educação Temática Digital Campinas, SP v.19 $\quad$ n.1 $\quad$ p. 283-304 jan./mar. 2017 
Vejamos como esse elemento se efetivou no município investigado por meio do discurso pedagógico (DP) de uma das técnicas da SMEC acerca do processo de constituição do Decreto Municipal que instituiu a política de educar para as relações etnicorraciais:

\begin{abstract}
A gente percebeu que tínhamos que dar uma formalidade, porque na gestão existe uma lei maior. Tivemos que fazer uma regulamentação a nível municipal. A nossa preocupação era que tivesse alguma coisa ligada a essa formalidade. Então, foi a partir daí que surgiu a ideia da gente criar um decreto, fazer um decreto que normatizaria como deveria funcionar a questão da Educação e Diversidade no município e, dentro desse decreto, a gente previa as datas que eram importantes ser trabalhadas no município, como deveriam funcionar, os princípios orientadores, a abrangência do tema e também a criação de um Núcleo (Carolina Maria).
\end{abstract}

De acordo com o discurso pedagógico do documento local, que atua como campo recontextualizador pedagógico, o Decreto Municipal seguiu os princípios do discurso oficial contido na Constituição Federal de 1988 para implementação da lei 10.639/03 no município. A referida Constituição, em seu discurso oficial, tem, no Artigo 3o, inciso IV, a garantia da promoção do bem de todos, sem preconceitos de origem, raça, sexo, cor, idade e quaisquer outras formas de discriminação. Baseado nessa perspectiva e no discurso oficial da Lei 10.639/03, a SMEC elabora e institui um decreto que apresenta como discurso recontextualizador pedagógico os seguintes princípios:

Art. 10- Fica instituído o Programa Municipal de Educação para Diversidade Cultural e Étnico-Racial, no Município (...) que tem por objetivo a implementação da Lei Federal no 10.639, de 09 de janeiro de 2003, do Perecer do CNE 003 de 10 de março de 2004 e da Resolução CNE/CP no 1 de 17 de junho de 2004.

Art. 2ㅇ - As escolas da Rede Municipal de Ensino de (...) incluirão os conteúdos de História e Cultura Afro-Brasileira e Africana nos programas, projetos, atividades e disciplinas de História, Língua Portuguesa, Literatura Geografia, Artes e Ciências e Matemática, de forma interdisciplinar.

Constatando que a temática racial poderia navegar na transversalidade de quase todas as disciplinas, no município investigado, além das áreas recomendadas pelo $\S 20$ da Lei 10.639/ 03 (Artes, Literatura e História Brasileira), podemos perceber que o Decreto municipal orienta para um desdobramento nas áreas de Língua Portuguesa, Geografia, História, Ciências e Matemática, de forma interdisciplinar. Esta abertura possibilita diversas visões sobre os diferentes grupos étnicos formados ao longo da história, além da possibilidade de analisar, através dessas disciplinas acopladas, os estudos específicos que cada uma desenvolverá, no foco do seu conteúdo programático sobre a população negra.

(C) ETD-Educação Temática Digital Campinas, SP v.19 $\quad$ n.1 $\quad$ p. 283-304 jan./mar. 2017 
Aqui podemos abordar o que Bernstein (1996) compreende por princípio ao conceituar o discurso pedagógico, pois o Decreto Municipal, ao instituir as disciplinas que trabalharão com conteúdos referentes aos negros, possibilita a criação das regras de reconhecimento e das regras de recontextualização, estas últimas, via prática pedagógica docente presente no currículo cotidiano. Para este sociólogo, tais princípios são as regras de reconhecimento, responsáveis por criar os meios que permitam distinguir os contextos, reconhecendo sua peculiaridade e as regras de realização, cujo foco são a regulação da criação e produção de relações especializadas dentro dos contextos. A abordagem das relações etnicorraciais a ser efetuada em cada disciplina curricular e esta, por sua vez, com sua linguagem especializada, possibilita a existência das regras de realização.

O Discurso Recontextualizador Oficial da Lei 10.639/03 e das Diretrizes Curriculares Nacionais para a Educação das Relações Etnicorraciais estabelece que os conteúdos referentes à história e cultura afro-brasileira sejam ministrados no âmbito de todo o currículo escolar, em especial nas áreas de educação artística e de literatura e história brasileira. Essas Diretrizes trazem indagações sobre como introduzir tais estudos sem cair numa perspectiva folclórica do multiculturalismo, que, apenas, fale dos ritos e mitos africanos, sem incorporar conteúdos mais críticos que dialoguem com essa temática de modo antirracista (CANEN, 2000).

De acordo com a análise de Bernstein (1996), o modo como a sociedade seleciona, classifica, distribui, transmite e avalia o conhecimento reflete a distribuição de poder e os princípios de controle social. Por isso, as diferenças e as mudanças na reorganização, na transmissão e na avaliação do conhecimento educacional devem ser consideradas uma área de interesse fundamental. Mudanças nos códigos educacionais traduzem alterações nas estruturas de poder e de controle que, por sua vez, afetarão a forma das relações sociais, bem como a forma como é pedagogicamente moldada a estrutura mental dos adquirentes.

Deste modo, compreender como o currículo está estruturalmente organizado implica pensar as relações de poder constituídas no âmbito do processo de formação, na instituição formadora ou na escola e situar as possibilidades de disciplinas ou propostas integradas para darem conta de finalidades educacionais e questões sociais mais amplas. A organização curricular e do conhecimento é perpassada por relações de poder que são diferentes nos campos científico, acadêmico e escolar - campo da produção, campo da recontextualização e o campo da reprodução (BERNSTEIN, 1996).

Para explicar a construção e a reprodução do discurso pedagógico, Bernstein (1996) apresenta três campos presentes na estrutura curricular: o campo de produção, o campo de

(C) ETD-Educação Temática Digital Campinas, SP v.19 $\quad$ n.1 $\quad$ p. 283-304 jan./mar. 2017 
recontextualização e o campo de reprodução. O primeiro consiste no campo encarregado da construção de novos discursos. Por exemplo, o discurso acadêmico sobre a História e Cultura Afro-Brasileira e Africana, para ser transformado em um discurso escolar sobre História e Cultura Afro-Brasileira e Africana, passa pela apropriação do campo de produção e transforma-o em discurso pedagógico, sendo o campo de recontextualização responsável por esse percurso.

Esse campo, quando composto pelo Estado e seus agentes, é chamado de campo de recontextualização oficial, e quando composto por formadores de professores, escritores de livros didáticos e periódicos especializados, é denominado de campo de recontextualização pedagógica. O terceiro campo é onde ocorre a prática pedagógica nas escolas, é onde acontece a materialização da disciplina. Portanto, a disciplina escolar é um discurso pedagógico construído por recontextualização pedagógica do discurso especializado da disciplina acadêmica (BERNSTEIN, 1996).

Em relação ao discurso acadêmico, quando este é movido pelo professor (agente de recontextualização) para a prática pedagógica, o discurso pedagógico opera em termos da seleção e da organização do que e como mover esse discurso em termos dos discursos já presentes e consolidados na prática pedagógica. Em vista disso, o discurso pedagógico, por meio das regras presentes, consolidadas e construídas socialmente no contexto escolar, controla o modo como um discurso pode ser posicionado na prática pedagógica (MAINARDES, 2010).

Assim, podemos perceber através das análises que o discurso produzido nas escolas sobre as relações etnicorraciais está sujeito aos princípios recontextualizadores provenientes de vários contextos: de contexto específico de uma dada escola e do controle externo do discurso pedagógico oficial. Do mesmo modo, o que é reproduzido pode ser afetado pelas relações de poder do campo recontextualizador entre a escola e o contexto cultural primário do adquirente (família/comunidade/relações de grupos de colegas). (BERNSTEIN, 1996).

Isso porque a dinâmica no processo de produção, distribuição, reprodução e mudança do discurso pedagógico ocorre numa arena de tensões, conflitos, resistências e inércia entre os envolvidos: os agentes políticos e administrativos do campo recontextualizador oficial, entre o campo recontextualizador pedagógico e o campo recontextualizador oficial; entre o contexto primário do adquirente (aluno) - (família, comunidade, relações de grupos de colegas) e as práticas na escola (BERNSTEIN, 1996).

(C) ETD-Educação Temática Digital Campinas, SP v.19 $\quad$ n.1 $\quad$ p. 283-304 jan./mar. 2017 
Podemos compreender através das análises que existe um elo de influencias entre os campos recontextualizadores (Oficial e Pedagógico) na proposta de implantação da Lei 10.639/03 no município de Jequié. Essa dinâmica de movimentação do discurso de seu lugar de origem para outro gera uma transformação ideológica. Isto porque estão em jogo visões de mundo, concepções, interesses diversos (especializados e/ou políticos) dos agentes recontextualizadores (produtores, reprodutores e adquirentes) dos discursos pedagógicos, ou seja, uma arena de conflitos que estrutura o campo da recontextualização.

Com efeito, o modelo proposto por Bernstein (1996) é complexo, pois desnuda as complexas interrelações entre o poder, o discurso pedagógico da reprodução e a distribuição de formas de consciência. Para este autor, todo discurso é um discurso recontextualizado; todo discurso é reposicionado; passa por transformações ideológicas do campo original de sua produção para o campo de sua reprodução.

A seguir, passamos a refletir sobre a influência dos discursos do campo recontextualizador pedagógico no processo de implementação da Lei 10.639/03 e o desenvolvimento de ações para o trabalho com a educação das relações etnicorraciais no município investigado.

\section{A CRIAÇÃO DO NÚCLEO DE ESTUDOS SOBRE A HISTÓRIA E CULTURA AFRO- BRASILEIRA E AFRICANA}

Desde o processo de implementação da Lei 10.639/03, o movimento negro local apontava a necessidade de um órgão na administração municipal que tratasse das discussões das relações etnicorraciais, do combate ao racismo e, especificamente, do ensino da história e cultura africana e afro-brasileira. Nesse contexto, representantes da sociedade civil e o movimento negro local passaram a reivindicar, de maneira mais contundente e articulada, o envolvimento direto do poder público com questões relacionadas à raça, etnia e gênero. Desse modo, o debate público e as iniciativas no campo das políticas de governo no município foram intensificados para fazer frente a esse conjunto cada vez mais evidente de desigualdades e cobrar da esfera municipal a efetivação da Lei 10.639/03.

Por força da Lei 10.639/03, a SMEC assumiu, em 2006, o compromisso de implementar políticas de promoção da igualdade racial nas escolas da rede municipal de ensino. Para isto, foram efetivadas parcerias com entidades do Movimento Negro, com a sociedade civil e também com a Universidade Estadual do Sudoeste da Bahia, através do Órgão de Educação e Relações Étnicas (Odeere). Isso nos aponta para o fato de que é

(C) ETD-Educação Temática Digital Campinas, SP v.19 $\quad$ n.1 $\quad$ p. 283-304 jan./mar. 2017 
possível afirmar que um discurso legal, de "força de lei", é uma construção social que busca alterar o outro por meio da recontextualização, pois é dito de várias formas para garantir o discurso pelas múltiplas linguagens presentes nos documentos oficiais (BERNSTEIN, 1996).

Dessa forma, a SMEC é eleita como lócus privilegiado para agenciar alterações nessa realidade, promovendo diversas ações, visando reduzir a reprodução de estereótipos e comportamentos que afetam o acesso a oportunidades iguais e a possibilidade de seu usufruto.

Entre as ações promovidas pela SMEC, destacamos como fato marcante a criação do Núcleo de Estudos sobre a História e Cultura Afro-Brasileira e Africana, instituído pelo Decreto Municipal 8.559/06, no Art. 6‥ O Núcleo surge da luta do movimento negro local, com o intuito de discutir e criar ações de fortalecimento do combate ao racismo nas escolas e na efetivação da Lei 10.639/03, tendo como preocupação inicial garantir o que estava posto na Lei e incluir nos currículos das instituições públicas e privadas a temática da história e cultura afro-brasileira e africana.

Nesse sentido, vale ressaltar o papel significativo, a contribuição e a influencia do movimento negro nas diferentes lutas sociais e político-culturais, entre as quais se encontra a luta contra o racismo e a própria constituição do movimento social negro no Brasil. A partir da metade do século XX e, especialmente, nos anos 70, do século XX, o Movimento Negro Unificado (MNU) já reivindicava, entre outras coisas, a reavaliação do papel do negro na história do Brasil e a valorização da cultura negra (GONÇALVES; GONÇALVES E SILVA, 2000).

Essa discussão intensifica-se durante o processo de construção do regime democrático em nosso país na década de 80 , do século XX, a partir da Constituição Federal de 1988, que refletia algumas das reivindicações de diferentes grupos sociais que até então não eram contemplados na construção dos currículos escolares de História, como se pode observar no discurso oficial do parágrafo $1 \stackrel{ }{1}$, do Art. 242 da referida Constituição: “O ensino da História do Brasil levará em conta as contribuições das diferentes culturas e etnias para a formação do povo brasileiro".

Sobre esse contexto, o discurso da entrevistada Lélia Gonzalez mostra que a "[...] Secretaria Municipal de Educação tem trabalhado para que a valorização da diversidade e a superação da desigualdade aconteçam de fato", por entender a necessidade de discutir de forma mais ampliada o tema das relações etnicorraciais, envolvendo todos os gestores neste processo de formação. Esse trabalho se deu na forma de congressos, seminários,

\section{(c) ETD-Educação Temática Digital Campinas, SP v.19 $\quad$ n.1 $\quad$ p. 283-304 jan./mar. 2017}


criação do Núcleo de Estudos História e Cultura Afro-brasileira e Africana, além de outros momentos de formação permanente por meio de cursos, palestras e debates.

Vejamos o que diz o discurso da entrevistada Dandara sobre a origem e o papel do Núcleo:

\begin{abstract}
A gente precisa ter um órgão que dê essa discussão, que passe por esse debate. Mas a gente não queria algo burocrático, queríamos uma coisa mais democrática, e a gente entendeu que o Núcleo seria a forma mais democrática da gente estar permitindo a discussão, que a coisa não ficasse centralizada só no gabinete, na prefeitura, com aquela visão muito limitada. Então, foi a partir daí que a gente criou o Núcleo (DANDARA).
\end{abstract}

Constatamos que as entrevistadas reconhecem a importância do papel do Núcleo, situando a temática das relações etnicorraciais como prioridade e estabelecendo estratégias para a implantação de políticas e do trabalho com as questões raciais. De acordo com o Decreto Municipal no 8.559/06, o objetivo da criação do Núcleo é fortalecer e institucionalizar as orientações disponibilizadas na Lei no 10.639/2003, nas instituições educacionais de ensino.

Nessa mesma linha de pensamento, as entrevistadas apontam que o Núcleo tem por objetivo estabelecer uma política que possibilite a valorização da diversidade etnicorracial e de gênero com o intuito de proporcionar a ampliação da temática sobre a diversidade nas escolas municipais, fazendo cumprir a Lei 10639/2003.

Deste modo, conforme afirma Dandara, "[...] o Núcleo veio como uma forma de apoiar os professores em suas práticas para que estas sejam feitas com o intuito de negar os estereótipos, valores e concepções preconceituosas presentes que se reproduzem no contexto escolar".

No que diz respeito à composição do Núcleo, buscaram-se pessoas que fossem vinculadas ao tema da cultura afro-brasileira e a estudos africanos, representantes ligados ao estudo e à pesquisa sobre a temática das relações etnicorraciais. $O$ discurso a seguir mostra como foi pensado o processo de composição do núcleo:

A gente não queria cargo político, porque cargo fica sempre ao sabor dos interesses políticos. Então queríamos uma função, um técnico, mas que não fosse um cargo de confiança, mas que e tivesse uma sensibilidade com a temática, para coordenar esse Núcleo. (GONZÁLEZ).

(C) ETD- Educação Temática Digital Campinas, SP $\quad$ v.19 $\quad$ n.1 $\quad$ p. 283-304 jan./mar. 2017 
No Discurso Recontextualizador Pedagógico Oficial do Decreto, fica definido, em seu $\S 2$, que a nomeação dos membros do Núcleo será por ato do Prefeito Municipal. No § 10, fica instituído que o Núcleo será composto por um grupo permanente de estudos e pesquisas sobre a temática com a seguinte composição:

I. 1 (um) representante da Secretaria Municipal de Educação e Cultura;

II. 2 (dois) representantes dos Diretores de Escolas Municipais;

III.1 (um) representante de dirigente de escola privada de Educação Infantil;

IV. 2 (dois) docentes representantes das Unidades Escolares Municipais;

V.1 (um) docente representante da rede privada (da educação Infantil);

VI. 1 (um) representante do Conselho Municipal de Educação;

VII. 1 (um) representante da União dos Negros (UNEJE);

VIII. 1 (um) representante do Movimento Mocambo Odara;

IX. 1 (um) representante da Comissão de Gênero e Raça da Câmara de Vereadores;

X. 1 (um) representante do Órgão de Educação e Relações Étnicas, com Ênfase em Cultura Afro-Brasileiras (Odeere/UESB );

XI. 1 (um) representante do Conselho Municipal de Cultura.

Podemos perceber que existe uma contradição entre o discurso pedagógico da entrevista com o discurso pedagógico recontextualizador oficial. Isso nos leva a afirmar que a escolha dos representantes do Núcleo acaba sendo feita por meio de indicação, que, por sua vez, receberá influencias do campo recontextualizador pedagógico oficial (CRPO), situação que acontece quando os agentes passam a trabalhar diretamente para o Estado e, consequentemente, os discursos recontextualizadores receberão mais influencias e efeitos ideológicos (BERNSTEIN, 1996).

Com base no conceito de recontextualização, podemos perceber que a política de criação do núcleo sofre influências de segmentos locais que, ao chegar ao contexto da prática, são testadas, experimentadas e recriadas. Nesse processo de recontextualização em que o discurso se insere, este passa também a adquirir um novo significado, mesmo que ele esteja fortemente relacionados a outros tempos e espaços.

Fica evidente que o funcionamento e a realização de ações do Núcleo dependem muito da relação estabelecida com os representantes e com quem estiver à frente da SMEC. O Núcleo não possui uma autonomia administrativa, uma vez que o desenvolvimento do

(C) ETD-Educação Temática Digital Campinas, SP v.19 $\quad$ n.1 $\quad$ p. 283-304 jan./mar. 2017 
trabalho e das ações deste fica a mercê da vontade dos gestores. Essa situação deixa o Núcleo fragilizado e influencia direta e indiretamente na visibilidade e na eficácia das ações. Uma vez que essas ações são influenciadas pelas orientações de nível federal, a materialização em nível local acaba sendo influenciada pelas representações políticas e de concepções dos que executam as políticas do município, principalmente as do recorte da educação das relações etnicorraciais, por isso a preocupação evidenciada anteriormente na entrevista realizada com Carolina Maria.

Para subsidiar o trabalho com a temática das relações etnicorraciais e promover discussões sobre questões relativas ao negro, incentivando as políticas de reparação no tocante às injustiças sociais, culturais, o Núcleo elegeu três eixos de trabalho: a formação de professores, o investimento nos materiais didático-pedagógicos e a construção de uma política para a implementação da Lei que passava pelo eixo central da educação do município, que era a inclusão.

Com base na teoria do Discurso Pedagógico (1996), esses eixos atuam como campo recontextualizador pedagógico. As propostas e ações de nível local seguem uma lógica assentada nos mecanismos de poder local e fortemente influenciadas pelas representações e concepções que circulam nas diversas formas de interações e contextos existentes.

Isso acontece com a política curricular do munícipio, com as políticas de promoção da igualdade racial e com a implementação da Lei 10.639/03; isto porque, ao se materializarem, essas políticas passam pelo processo de recontextualização em que seus discursos sofrem influências de outros contextos, deslocando-os dos contextos originais, passando a constituir uma nova ordem, um novo sentido vindo a propor, a estabelecer, a definir e a controlar os conteúdos e as relações com os processos de transmissão e reprodução do conhecimento escolar (BERNSTEIN, 1996).

No que diz respeito à situação atual do Núcleo, este se encontra em reformulação, caminhando para o fortalecimento da discussão e necessitando de mais incentivo, de mais suporte da SMEC. Existe uma proposta de se criar um Núcleo Interdisciplinar para atender a adequação da Secadi. Sobre esse aspecto, vejamos o discurso abaixo:

Eu, particularmente, não concordo, mas é uma decisão de governo, do MEC. A Secadi agora integrou tudo num pacote só. Está na mesma Secretaria: Educação do Campo, Educação Especial, Educação e Diversidade, Educação de Jovens e Adultos, Educação Quilombola, Educação da Juventude e Educação Indígena. Se a gente tem esse entendimento nos municípios, a gente vai criar núcleos integrados. Teoricamente é ótimo, até para gerenciamento, administrar recursos é bom, mas

(C) ETD-Educação Temática Digital Campinas, SP v.19 n.1 $\quad$ p. 283-304 jan./mar. 2017 
na prática não funciona. [...] Quem discute comunidade indígena não discute comunidade quilombola. Não é a mesma coisa. Não dá pra botar no mesmo pacote. Se criar esse núcleo, se o fizer, já sabe que tem que ter representações. Enfraquece, lógico! Não são as mesmas coisas e não podem ser tratadas da mesma forma. (GONZÁLEZ).

Compreendemos a iniciativa da Secretaria de Educação Continuada, Alfabetização e Diversidade e Inclusão (Secadi), em propor às Secretarias de Educação um trabalho interdisciplinar, tendo em vista o avanço de um conjunto de políticas públicas e de ações afirmativas que demandam iniciativas do município. Essa articulação pode facilitar o trabalho da gestão de recursos, além de proporcionar o diálogo entre as temáticas para a construção de ações conjuntas.

Entretanto, é válido ressaltar o cuidado com essa integração, como mostra o discurso da entrevistada. Devido à diversidade de demanda e à quantidade de ações que as Secretarias Municipais apresentam em seu organograma, corre-se o risco de haver alguma limitação, podendo-se atender mais às necessidades gerais e comuns aos eixos, deixando-se de lado necessidades específicas das temáticas em questão. Em se tratando das relações etnicorraciais, em que já existe uma resistência em trabalhar com essa temática, esta, infelizmente, poderá ser considerada menos prioritária. Reside nisso a necessidade de investigar de que forma os municípios vem incorporando o trabalho com esse conteúdo previsto na Lei 10639/03 e artigo 26A da Lei 9394/96 em seus Planos Municipais de Educação (PME) e em conformidade com as 20 metas para a educação, previstas no Plano Nacional de Educação (PNE), particularmente as metas 8, 15 e 16 (BRASIL, 2014). No que diz respeito às metas estruturantes que visam garantir o direito à educação básica de qualidade $(1,2,3,5,6,7,9,10)$, dispostas no PNE, entendemos que a educação das relações etnicorraciais deve transversalizá-las.

Nessa perspectiva, a Secadi, como órgão responsável, no MEC, pelos temas da diversidade, precisa ter um olhar mais apurado para as diversidades de grupos, sem perder de vista as especificidades destes. Para isso, é necessário o acompanhamento das ações para se buscar resolver os equívocos suscitados pela aplicação de recursos, sobretudo, na implementação de ações no campo relações etnicorraciais.

Com base na teoria do discurso pedagógico, essas instâncias governamentais (Secadi, Sepromi, MEC) atuam como campo recontextualizador oficial, uma vez que é regulada diretamente pelo Estado, através da administração pública que, por sua vez, preocupa-se com a regulação e circulação dos contextos da produção e reprodução, sendo que esses campos são afetados pelo controle simbólico (BERNSTEIN, 1996). No contexto da

(C) ETD-Educação Temática Digital Campinas, SP v.19 $\quad$ n.1 $\quad$ p. 283-304 jan./mar. 2017 
Lei 10.639/03, essas instâncias governamentais selecionam, classificam os conteúdos a serem transmitidos e indicam possibilidades de como devem ser desenvolvidas essa transmissão.

\section{CONSIDERAÇÕES FINAIS}

Tomando como base o último livro de Bernstein (1998, p.92), intitulado Pedagogía, control simbólico y identidad, podemos afirmar que o conhecimento oficial, isto é, "o conhecimento educativo que o Estado constrói e distribui para as instituições educativas", projeta identidades pedagógicas diferentes, uma vez que as lutas dos diferentes grupos (no caso aqui analisado, o movimento negro, a universidade, as editoras) "buscam converter suas inclinações e centros de atenção em normas e práticas do Estado" (LOPES, 2002, p.94).

O modelo desenvolvido por Bernstein para a análise das identidades pedagógicas possibilita a compreensão da reforma efetuada pelo Estado no campo oficial a partir de uma tipologia em que cada modalidade implica posturas (inclinações, focos e perspectivas) cuja finalidade é "regular e dirigir a mudança moral, cultural e econômica" (BERNSTEIN, 1998, p.93). Contudo, de acordo com Lopes (2002, p.94), “(...) tais identidades não estão isentas dos efeitos de construções identitárias externas ao campo oficial".

Para Bernstein (1998, p.94), "Duas das identidades das quais tratarei geram-se mediante os recursos gestionados pelo Estado: recursos centrados e as outras duas identidades se geram a partir de recursos locais, em que as instituições afetadas têm certa autonomia em relação a seus recursos: recursos des-centrados". As identidades pedagógicas abrangem quatro modalidades e, consequentemente, quatro posturas: retrospectiva (postura conservadora antiga), prospectiva (postura neoconservadora), descentrada (sic) de mercado (postura neoliberal) e des-centrada terapêutica (postura profissional). Importa salientar que esses tipos de identidades não ocorrem de maneira pura e/ou excludente no processo de reforma curricular e que "tais posturas no interior do campo recontextualizador oficial atuam em oposição e cooperação, ou podem ser excluídas do campo por não haver quem ou o que as legitime neste momento histórico" (LOPES, 2002, p.105).

(C) ETD-Educação Temática Digital Campinas, SP v.19 $\quad$ n.1 $\quad$ p. 283-304 jan./mar. 2017 
Assim, no caso específico da educação para as relações etnicorraciais, podemos encontrar elementos que nos permitem apontar para dois tipos de identidades pedagógicas: as retrospectivas e as des-centradas terapêuticas, produzidas no embate dos campos recontextualizadores e da pressão do movimento social negro.

As Diretrizes Curriculares para o ensino de história e cultura africana e afrobrasileira, documento do campo recontextualizador oficial, não apresentam listagem de conteúdos a serem trabalhados, característicos da identidade pedagógica prospectiva. No entanto, a aprovação desse documento, assim como da Lei 10639/03, ensejou uma série de produções de acadêmicos (artigos, livros, programas de TV, comentários nas redes sociais) de discursos em que evidenciamos um retorno às grandes narrativas do passado, com evidente hierarquização dos conhecimentos curriculares, valorizando-se, sobremaneira, os conteúdos referentes à visão de mundo europeizada.

Na outra ponta, a difícil e lenta implementação e, em vários casos, a retirada das discussões dos planos municipais de educação das relações etnicorraciais, apontam para a presença das identidades des-centradas terapêuticas, pois poucos efeitos são produzidos no nível dos Estados, estando nelas presentes os elementos característicos de uma pedagogia invisível.

A implementação da Lei 10639/03 configura-se como um caminho de conquistas na rede municipal de ensino do município investigado, principalmente quando verificamos que grande parte dos municípios baianos sequer realizou alguma política para implementar o ensino de história e cultura africana e afro-brasileira nos currículos. No entanto, é ingenuidade pensar que sua implementação, por si só, garantirá mudanças significativas nas relações históricas que excluem o negro na sociedade. Ela se constitui a partir de ações que podem ser coletivas e individuais, implicando, dentre outras, em alterações no currículo, nas políticas e práticas de formação docente, na gestão educacional. As identidades descentradas terapêuticas são evidentes na rede investigada. Classificação e enquadramentos fracos fazem com que, mesmo com a existência de um documento do campo recontextualizador pedagógico oficial, neste caso a SMEC, as escolas não percebam a necessidade de trabalho com as relações etnicorraciais no currículo.

Com base na análise dos documentos federais e municipais, foi possível compreender que, para além do aporte legal, é no cotidiano das instituições governamentais, compostas por sujeitos que produzem políticas curriculares, que as ações e as políticas serão ou não levadas em consideração, com maior ou menor grau de reconhecimento. As considerações das entrevistas nos levam ao reconhecimento de que,

(C) ETD-Educação Temática Digital Campinas, SP v.19 $\quad$ n.1 $\quad$ p. 283-304 jan./mar. 2017 
apesar dos desafios enfrentados, o trabalho do Núcleo e da SMEC teve repercussão no campo político e pedagógico, pois possibilitou aos grupos e à sociedade momentos de reflexão sobre a questão de afirmar a cultura afro-brasileira e de combater o preconceito com mais vigor.

\section{REFERÊNCIAS}

ARROYO, Miguel. Os coletivos empobrecidos repolitizam os currículos. In: José Gimeno Sacristán (Org.). Saberes e incertezas sobre o currículo. Porto Alegre: Penso, 2013.

BARBOSA, Mirela V.F. Implementação de políticas públicas com a perspectiva da ação intersetorial: uma análise comparada do Programa Travessia e do Programa Cultivar, Nutrir e Educar. Dissertação (Mestrado em Ciência Política). UFMG, Faculdade de Filosofia e Ciências Humanas, Belo Horizonte, 2014.

BERNSTEIN, Basil. A estruturação do discurso pedagógico: códigos, classes e controle. Petrópolis: Vozes, 1996.

Pedagogía, control simbólico y identidad. Madri: Moratta, 1999.

BRASIL. Lei 10639/03. Altera a Lei $\mathrm{n}$-9.394, de 20 de dezembro de 1996, que estabelece as diretrizes e bases da educação nacional, para incluir no currículo oficial da Rede de Ensino a obrigatoriedade da temática "História e Cultura Afro-Brasileira", e dá outras providências. Brasilia, 2003.

BRASIL. Lei 13.005, de 25 de junho de 2014. Aprova o Plano Nacional de Educação. Brasília, Presidência da República, 2014.

CANEN, Ana. Educação multicultural, identidade nacional e pluralidade cultural: tensões e implicações curriculares. Cadernos de Pesquisa, São Paulo, n. 111, p. 134-149, 2000.

CAVALLEIRO, Eliane; MARQUES, A. Políticas públicas, desigualdades raciais e de gênero: repensando valores, princípios e práticas. Anais Fazendo Gênero 08, Florianópolis, 2008.

CHAUI, Marilena. Brasil: mito fundador e sociedade autoritária. São Paulo: Fundação Perseu Abramo, 2000.

COELHO, Wilma Nazaré Baia.; SILVA, R.N.B. Relações raciais e educação: o estado da arte. Revista Teias, vol.14, n.31, p. 121-146, 2013.

FILICE, Renisia Cristina. Raça e classe na gestão da educação básica brasileira. Tese (Doutorado em Educação). Faculdade de Educação, Universidade de Brasília, Brasília, 2010.

GOODSON, I. Currículo: teoria e história. Petrópolis: Vozes, 1995.

GOMES, Nilma. Relações étnico-raciais, educação e descolonização dos currículos. Currículo sem Fronteiras, vol.12, n.01, p.98-109, 2012.

(C) ETD- Educação Temática Digital Campinas, SP v.19 n.1 $\quad$ p. 283-304 jan./mar. 2017 
GONÇALVES, Luis Alberto Oliveira; GONÇALVES E SILVA, Petronilha Beatriz. Movimento negro e educação. Revista Brasileira de Educação, v. 15, n.15, p. 134-158, 2000.

HASENBALG, Carlos. Discriminação e desigualdades raciais no Brasil. 2.ed. Belo Horizonte: Ed. UFMG, 2005.

LADISON-BILINGS, Gloria. Os guardiões de sonhos: o ensino bem-sucedido de crianças afroamericanas. Belo Horizonte: Autêntica, 2008.

LOPES, A.R.C. Identidades pedagógicas projetadas pela reforma do ensino médio no Brasil. In: MOREIRA, A.F.B.; MACEDO, E. (Orgs.). Currículo, práticas pedagógicas e identidade. Porto: Porto Editora, 2002.

MAINARDES, Jefferson. A teoria de Basil Bernstein e algumas de suas contribuições para as pesquisas sobre políticas educacionais e curriculares. Revista Teias, v. 11, n. 22, p. 1-24, maio/agosto, 2010.

MORAIS, A.M.; NEVES, I.P. A teoria de Bernstein: alguns aspectos fundamentais. Práxis Educativa, v.2, n.2, p. 115-130, 2007.

PAULA, Benjamin Xavier de; GUIMARÃES, Selva. 10 anos da Lei Federal 10639/03 e a formação de professores: uma leitura de pesquisas científicas. Educação e Pesquisa, n.40, vol.2, p. 435-448, 2014.

PONTES, C.; MACEDO, E. Demandas raciais no Brasil e política curricular. Cadernos de Educação, n.38, p.175-200, 2011.

ROMÃO, Jeruse. O educador, a educação e a construção de uma auto-estima positiva no educando negro: In: CAVALLEIRO, Eliane. Racismo e anti-racismo na educação: repensando nossa escola. São Paulo: Selo Negro, 2001.

SANTOMÉ, J.T. As culturas negadas e silenciadas no currículo. In: SILVA, T.T. (Org.). Territórios contestados: o currículo e os novos mapas políticos e culturais. Petrópolis: Vozes, 1999.

SANTOS, L.L.C.P. Bernstein e o campo educacional: relevância, influência e incompreensões. Cadernos de Pesquisa, n.120, p.15-49, 2003.

SANTOS, C.V.B. Sentidos atribuídos a categorias do campo das relações etnicorraciais no âmbito de currículos e práticas. Dissertação (Mestrado em Educação). Universidade Estadual do Sudoeste da Bahia, Vitória da Conquista, 2015.

\footnotetext{
'Revisão gramatical do texto pela equipe da revista
}

(C) ETD-Educação Temática Digital Campinas, SP v.19 n.1 $\quad$ p. 283-304 jan./mar. 2017 